\title{
EXTRACTABLE ORGANIC COMPOUNDS IN MIDWEST RAIN AND SNOW
}

\author{
Philip A. MeYers \\ Department of Atmospheric and Oceanic Science, The University of Michigan, Ann Arbor, MI 48109, U.S.A. \\ and \\ RONALD A. HITES \\ School of Public and Environmental Affairs and Department of Chemistry, Indiana University, \\ Bloomington, IN 47405, U.S.A.
}

(First received 6 July 1981 and in final form 3 November 1981)

\begin{abstract}
A portion of the organic compounds in subaqueous sediments originates from airborne materials transported from distant sources. We have analyzed by GC and GC-MS the organic compounds extractable with dichloromethane in rain and snow samples collected over an 8-month period in southern Indiana. Straightchain fatty acids and hydrocarbons from biological sources dominate the compositions, and these show only minor seasonal changes. Concentrations of organic compounds appear to be inversely related to volume of precipitation. Much of this organic material appears to have been transported from afar, although local inputs are evident. Estimated flux rates to sediments are small compared to organic matter accumulation rates in Lake Michigan.
\end{abstract}

\section{INTRODUCTION}

Organic materials found in subaqueous sediments originate from a variety of sources. Some are created in the overlying water by aquatic life and carried to the bottom by sinking particles, while others are synthesized by benthic organisms. In addition, landderived natural and anthropogenic organic matter is commonly transported to lakes and seas by river flow and by winds. The atmospheric component of transport can be especially important to water bodies having relatively large pluvial inputs and relatively low rates of autochthonous organic matter production, such as the Great Lakes and the oceans. As an example, Andren and Strand (1981) estimate that atmospheric input of organic carbon is equal to that of river input to Lake Michigan waters.

Although the organic matter content of the troposphere has not been extensively studied, existing reports indicate it to be a significant component of the global cycling of many forms of organic carbon. For instance, Rasmussen (1972) estimates that trees emit 175 $\mathrm{Mt}^{-1}$ of volatile isoprene and monoterpene hydrocarbons to the atmosphere, six times more than the worldwide activities of man. Simoneit (1979) concludes that eolian dusts can make a large contribution to the organic fraction of certain oceanic sediments deposited over geologic time periods. An important part of this airborne organic matter is derived from land sources, even far at sea (Simoneit, 1980). Fine-size particles, which can easily be carried long distances by winds, carry most of the hydrocarbon and hydrocarbon-like component of atmospheric dusts and aerosols (Van
Vaeck and Van Cauwenburghe, 1978; Van Vaeck et al., 1979) which include the biomarker compounds used to identify organic matter sources. This helps to explain the extensive transport of terrigenous organic materials and their strong signal in samples collected far from land.

Distributions of aliphatic hydrocarbons have been determined in air samples collected over the North Atlantic Ocean (Eichmann et al., 1979), the Indian Ocean (Eichmann et al., 1980), and the Pacific Ocean (Gagosian et al, 1981a, 1981b). Aliphatic and polycyclic aromatic hydrocarbon (PAH) concentrations have been measured in air from northern Europe (Broddin et al, 1980). These studies show that a wide range of hydrocarbons exist in air from both urban and non-urban regions. Some of these materials settle from the troposphere in association with dust particles; others are carried down by incorporation into precipitation. Lunde et al. (1977) list a wide range of organic micropollutants found in rain and snow samples from Norway, and Gagosian et al. (1981b) show the presence of land plant lipids in rain samples collected at Enewetak Island in the Pacific. These represent airborne materials scavenged from the atmosphere and carried down by precipitation.

In view of the potential significance of precipitation as an input mechanism for the organic content of subaqueous sediments in basins such as the Great Lakes, we studied the extractable organic matter in rain and snow collected during the fall, winter and spring at a midwest location. This report presents the results of our investigation. 


\section{EXPERIMENTAL}

The sample location was situated in a semi-rural area on the northern outskirts of Bloomington, Indiana. The nearest large source of smoke was the Indiana University coal-fired power plant about $2.4 \mathrm{~km}$ distant. The sample collector was $3 \mathrm{~m}$ off the ground on the edge of a raised deck attached to a private all-electric residence. No trees were closer than $10 \mathrm{~m}$, and none overhung the collector.

Rain and snow were collected on a round aluminum dish with a surface area of $3165 \mathrm{~cm}^{2}$. The collecting apparatus was set up only during a precipitation event in order to avoid collection of dryfall. Rainwater fowed through a small hole in the depressed center of the collector into a solvent-rinsed glass $19 /$ bottle. Snow collected on the dish was melted at room temperature and allowed to drip through the central hole into the bottle. A small amount of methylene chloride was used as a preservative in the bottle.

Extraction of nonfiltered rain water and snow meltwater was done in the collection bottle. Concentrated $\mathrm{HCl}$ was added to bring the $\mathrm{pH}$ to between 1 and 2, and organic compounds were extracted into methylene chloride (Nanograde, Mallinkdrodt) by magnetic stirring. After the organic and aqueous phases had been separated, the volume of the extracted water was measured. The organic extract was concentrated on a rotary evaporator under reduced pressure and then transferred to a small vial. The remaining solvent was evaporated with a nitrogen stream. For GC and GC-MS analyses, $100 \mu l$ of methylene chloride was added and a $\mu l$ of this was injected into the instrument.

After preliminary GC and GC-MS analyses, the extracts were methylated with a mixture of $0.6 \mathrm{ml}$ toluene and $2 \mathrm{ml}$ boron trifiuoride in methanol (Supelco, Inc., Bellefonte, PA) by heating in a screwcap tube at $100^{\circ} \mathrm{C}$ for $5 \mathrm{~min}$. Three millilitres of water and $2 \mathrm{~m}$ l hexane were added to the cooled tubes, and the organic layer removed. The aqueous phase was extracted twice more with $3 \mathrm{ml}$ portions of hexane, and the extracts combined and evaporated under nitrogen.

GC analyses were done with a Carlo Erba FID gas chromatograph equipped with a $20 \mathrm{~m}$ SE52 glass capillary column $(0.25 \mathrm{~mm}$ ID). Helium carrier gas was adjusted to a flow velocity of $50 \mathrm{~cm} \mathrm{~s}^{-1}$ at $280^{\circ} \mathrm{C}$. The column oven was heated from $80^{\circ}$ to $280^{\circ} \mathrm{C}$ at a rate of $5^{\circ} \mathrm{C} \mathrm{min}^{-1}$. Samples were injected in a splitless mode; after 50 sec the split valve was opened to a split ratio which optimized flow rates. FID response was calibrated periodically with quantitative $n$ alkane and PAH standards. Samples were quantified by comparison of peak areas with those of the standards. A Hewlett-Packard 5982A mass spectrometer interfaced to a 5933 data system and a 5710 gas chromatograph was used for GC-MS analyses.

One rain sample was extracted a second time to measure extraction efficiency and to determine the amount of contaminants contributed by the overall procedure. An ad. ditional $3^{\circ}$ of fatty acids and alkanes was provided by this extract, showing that the single-step extraction was effective and that little contamination occurred.

\section{RESULTS AND DISCUSSION}

The precipitation extracts contained a large number of compounds resolvable by our GC procedure. A typical chromatogram is presented in Fig. 1. This particular extract came from a moderately heavy snowfall associated with a cold front crossing southern Indiana on 15 February 1980. Nearly all of the compounds representing the major peaks in Fig. 1, as well as many of the minor ones, have been identified as biologically derived organic molecules. All of the other precipitation samples contain very similar distributions of components, although their individual amounts vary. These components are dominated by straight-chain monocarboxylic acids having 14,16 and 18 carbon atoms. As concluded by Simoneit (1980), such fatty acids indicate recent biosynthesis and in eolian samples are probably derived from microbial sources. Straight-chain saturated hydrocarbons are also important components of this snow extract. Alkanes having chain-lengths of 27 and 29 carbon atoms are the major hydrocarbons although $\mathrm{C}_{25}$ and $\mathrm{C}_{31}$ are also clearly present. Such strong odd-carbon predominance is characteristic of biological hydro-

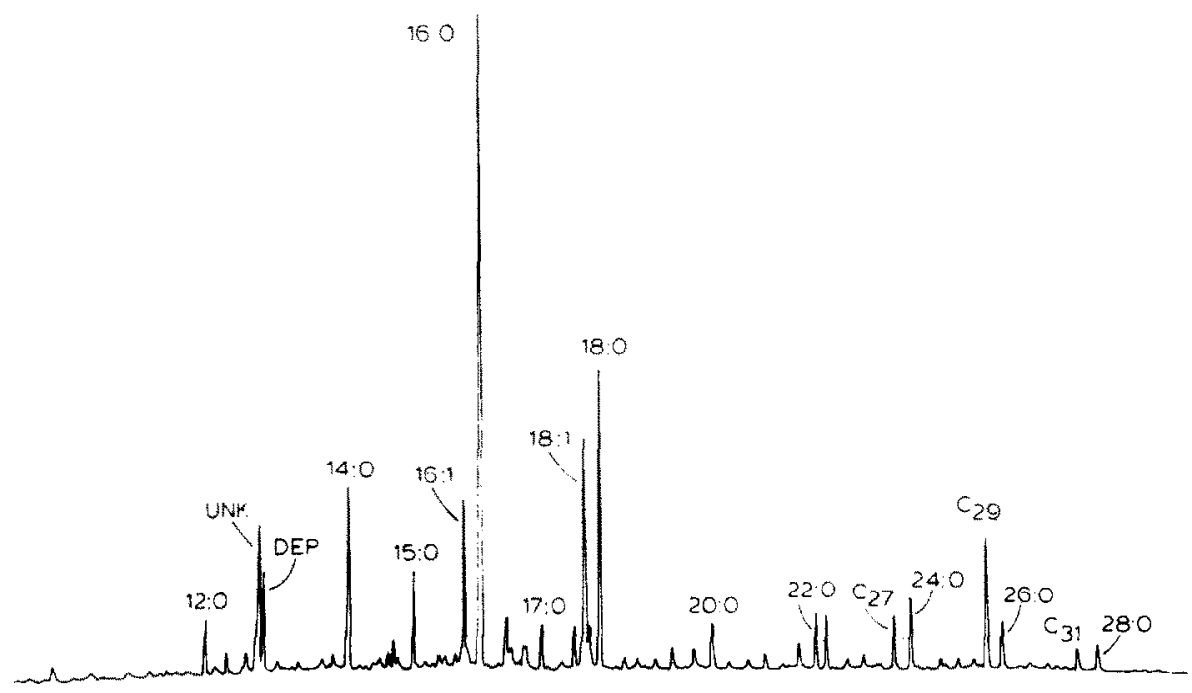

Fig. 1. Chromatogram of extract of snow collected on 15 February 1980 . Fatty acids identified by carbon chainlength and number of double bonds. n-Alkanes labeled as $\mathrm{C}_{27}, \mathrm{C}_{29}$, etc. DEP is diethyl phthalate. GC conditions: $20 \mathrm{~m}$ SE52 glass capillary column operated from 80 to $280^{\circ} \mathrm{C}$, splitless injection. 
carbons and is not commonly found in geological materials such as petroleum. This, combined with the long chain-lengths, suggests a plant wax origin (Simoneit, 1977, 1978). Similar odd-carbon predominance of $C_{27}$ to $C_{31}$ n-alkanes has been reported in aerosols (Van Vaeck and Van Cauwenberghe, 1978; Van Vaeck et al, 1979) and evidently indicates an important land plant contribution on the hydrocarbon loading of the atmosphere (Broddin et al., 1980; Simoneit, 1981).

The fatty acids and hydrocarbons isolated from these unfiltered rain and snow samples probably reside in the particulate phase. Gagosian et al., (1981b) compare distributions of particulate and vapor phase $n$-alkanes collected at Enewetak Atoll. The particulate distribution is virtually the same as those in our precipitation samples. Furthermore, they analyzed for fatty acids and fatty alcohols in the vapor phase and found none, indicating that these high-molecular weight, low-vapor-pressure compounds exist predominantly associated with particles in the atmosphere.

Noticeably lacking in all of our samples are significant amounts of aliphatic hydrocarbons with less than 25 carbons or of "humps" of unresolved hydrocarbon mixtures. Broddin et al. (1980) found that $C_{24}$ to $C_{26}$ hydrocarbons believed derived from fossil-fuel combustion dominated $n$-alkanes distributions in aerosols collected in urban areas during the winter. They also noted that these petroleum-type contributions became less in progressively less urbanized areas. Similarly, Simoneit et al. (1980) found petroleum residues to be greater in aerosols collected during the winter in the Lake Tahoe region than in those from summer periods. In the chromatogram of a winter snow extract in Fig. 1, aliphatic hydrocarbons which might originate from petroleum are not major components. The absence of important amounts of petroleum-type $n$-alkanes or of an unresolved complex mixture of hydrocarbons may reflect either the predominantly rural character of southern Indiana or a difference in fossil fuels. Coal is the primary fuel for large-scale industrial use and power generation in this region. While it is possible that a different suite of compounds would be emitted from coal combustion than from petroleum combustion, Tripp et al. (1981) have noted that aliphatic hydrocarbon distributions of unburnt coal and number 2 fuel oil are similar. Hence, hydrocarbon patterns of these precipitation samples do not appear to include important contributions from fuel combustion.

Precipitation samples collected during the winter months of January and February contained relatively larger contributions of "unknown 71" and diethyl phthalate. These do not seem to be laboratory contaminants in these samples. The large peak preceding diethyl phthalate in Fig. 1 is presently an unidentified compound. GC-MS of this peak gives a single major ion of $\mathrm{M} / \mathrm{e} 71$, hence its label of "unknown 71 ". Because this peak appears quite prominently in winter precipitation samples, its origin may be related to coal combustion. Proper identification of "unknown 71" remains enigmatic.

Another group of extractable organic compounds missing from Fig. 1 is straight-chain alcohols. These have been reported as major organic components of eolian particles from over the Atlantic (Simoneit et al., 1977) and the Pacific (Gagosian et al., 1981b) and from over North American rural areas (Simoneit, 1980). Because our extraction and analysis methods detect high molecular weight alcohols, it seems likely their presence is masked in our unfractionated samples by much higher concentrations of long-chain acids and hydrocarbons. Aliphatic alcohols are not prominent in our precipitation samples nor in those of Lunde (1977), although they are important in atmospheric aerosols (Simoneit, 1977; Broddin et al., 1980) and in oceanic rains (Gagosian et al., 1981b).

Table 1 summarizes concentrations of organic compound groupings extracted from precipitation samples collected during our study. Fatty acids dominate in most of these samples, constituting between 50 and $85 \%$ of the total extractable materials. In contrast to the increases in aerosol aliphatic hydrocarbon concentrations found during the winter by Broddin et al. (1980), no overall seasonal change is evident in total $n$ alkane concentrations. However, small but significant differences do exist in the concentrations of materials contained within types of precipitation, and there are seasonal changes in distributions of individual fatty acids and hydrocarbons. The qualitative differences between samples collected at different times are greater than those present in the rain samples collected on 21-22 December and on 22-24 December, representing the first and second halves of a single precipitation event. Fatty acid and $n$-alkane distributions are quite similar in these two samples, and concentration patterns are also reasonably close. Excellent agreement in $n$-alkane and fatty alcohol contents of rain samples collected a day apart (Gagosian et al., 1981b) shows that closely spaced precipitation events of the same type can differ little in organic matter loading.

Some of the differences between extracts of rain, snow, and thunderstorm samples are shown in Fig. 2. These precipitation samples were collected during 7-day period in February 1980. The rain and snow samples result from the passage of a cold front and therefore represent different aspects of a single meteorological event. Concentrations of most extractable components are similar in these two samples, and their distributions are also alike. However, the snow extract contains twice as much unsaturated $C_{16}$ and $C_{18}$ acids as does the rain extract. These compounds are indicators of recent biogenesis. Because they are at higher concentrations in the snow than in the rain, these unsaturated acids may indicate a different source of organic matter. However, the close similarities in overall alkanoic acid and alkane distributions in Fig. 2 and in their concentrations in Table 1 do not support this suggestion. Both these samples appear to contain virtually the same extractable or- 
Table 1: Summary of organic materials extracted from southern Indiana precipitation

\begin{tabular}{|c|c|c|c|c|c|c|c|c|}
\hline \multirow[b]{2}{*}{ Date } & \multirow[b]{2}{*}{ Type } & \multicolumn{7}{|c|}{ Concentration, $\left(\mu \mathrm{g} /^{-1}\right)$} \\
\hline & & Vol (1). & $\begin{array}{c}\text { Total } \\
\text { extract }\end{array}$ & $\begin{array}{c}\text { All } \\
\text { FAME }\end{array}$ & $\begin{array}{l}\text { FAME } \\
\leqslant \mathrm{C} 20\end{array}$ & $\begin{array}{c}\text { FAME } \\
>\mathrm{C} 20\end{array}$ & $\underset{n \text {-alkanes }}{\text { All }}$ & $\frac{18: 1}{18: 0}$ \\
\hline 20 Oct 1979 & rain & 4.17 & 26 & 15 & 10 & 5 & 5 & 1.1 \\
\hline 1 Nov 1979 & rain & 8.96 & 18 & 10 & 8 & 2 & 4 & 0.6 \\
\hline 27 Nov 1979 & snow & 2.07 & 34 & 23 & 21 & 2 & $i$ & 1.0 \\
\hline 21-22 Dec 1979 & rain & 11.04 & 8 & 4 & 3 & 1 & 3 & 0.4 \\
\hline 22-24 Dec 1979 & rain & 15.68 & 10 & 6 & 4 & 2 & 3 & 0.8 \\
\hline 29-30 Jan 1980 & snow & 3.59 & 55 & 45 & 42 & 3 & 1 & 1.3 \\
\hline 5 Feb 1980 & snow & 3.57 & 12 & 6 & 5 & 1 & 0.4 & 1.5 \\
\hline 15 Feb 1980 & rain & 4.16 & 26 & 18 & 15 & 3 & 3 & 0.3 \\
\hline 15-16 Feb 1980 & snow & 3.59 & 24 & 18 & 16 & 2 & 2 & 0.8 \\
\hline 21 Feb 1980 & thunderstorm & 3.63 & 36 & 25 & 19 & 6 & 8 & 0.8 \\
\hline 27 Feb 1980 & snow & 3.15 & 26 & 18 & 14 & 4 & 3 & 1.0 \\
\hline 1 Mar 1980 & snow & 3.11 & 28 & 17 & 12 & 5 & 7 & 0.5 \\
\hline 5 Mar 1980 & rain & 4.47 & 43 & 37 & 33 & 4 & 2 & 0.5 \\
\hline 7 Mar 1980 & rain & 6.84 & 20 & 17 & 15 & 2 & 1 & 0.1 \\
\hline 13 Mar 1980 & snow & 6.95 & 34 & 23 & 18 & 5 & 5 & 0.1 \\
\hline 20-30 Mar 1980 & rain & 18.54 & 18 & 12 & 9 & 3 & 2 & 0.8 \\
\hline 3 Apr 1980 & thunderstorm & 6.45 & 29 & 19 & 15 & 4 & 7 & 1.8 \\
\hline 9-11 Apr 1980 & rain & 9.15 & 16 & 12 & 9 & 3 & 3 & 1.1 \\
\hline 14 Apr 1980 & rain & 7.11 & 28 & 18 & 13 & 5 & 6 & 1.2 \\
\hline 28 Apr 1980 & rain & 3.18 & 61 & 45 & 38 & 7 & 8 & 2.0 \\
\hline 11 May 1980 & thunderstorm & 1.91 & 69 & 38 & 31 & 7 & 7 & 4.1 \\
\hline 12 May 1980 & thunderstorm & 2.45 & 27 & 17 & is & 2 & 2 & 4.2 \\
\hline 16 May 1980 & rain & 17.75 & 42 & 34 & 29 & 5 & 4 & 13.9 \\
\hline
\end{tabular}
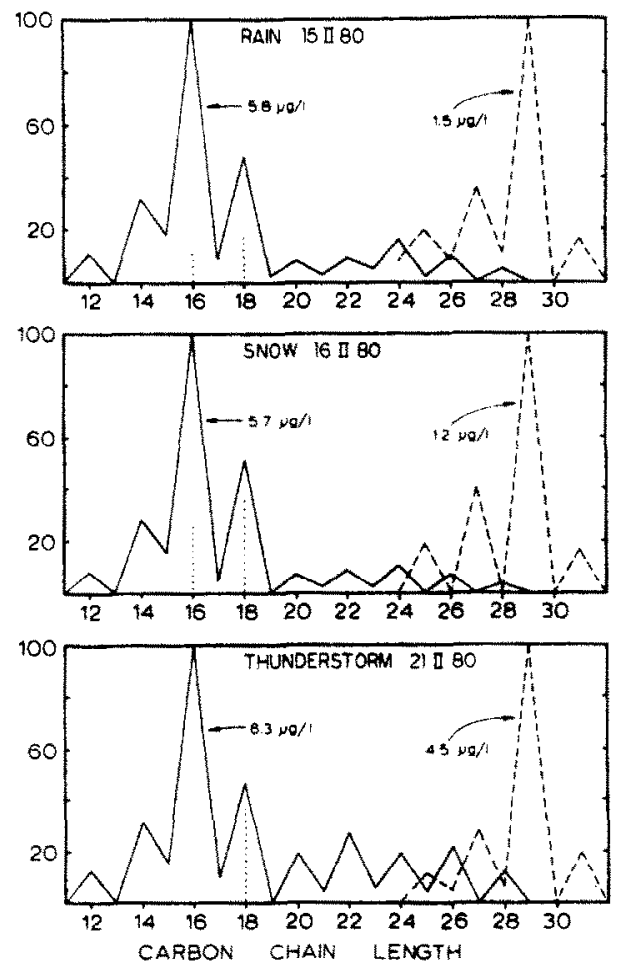

Fig. 2. Comparison of fatty acid and n-alkane contents of rain, snow, and thunderatorm enmples collected during one week in February 1980. Acids and alkanes normalized to the hargest component within each compound type. Saturated acids shown as solid lines; unsaturated acids as dotted lines; $n$ alkanes as dashed lines. ganic compounds. The enrichment in $C_{16}$ and $C_{18}$ alkenoic acids may reflect better scavenging of these more volatile compounds by snow than by rain. Indeed, other snow samples listed in Table $I$ have relatively high amounts of $<\mathrm{C}_{20}$ alkanoic acids, perhaps as a result of much more effective scavenging.

The amounts and types of extractable organic compounds in the thunderstorm sample in Fig. 2 are different from those in the rain and snow. More $>\mathrm{C}_{20}$ acids and more alkanes are present, and the ratio of $C_{18}$ to $C_{16}$ alkenoic acids is proportionately greater than in the rain and snow samples. The longer chain alkanoic acids and $n$-alkanes which originate from land plant cuticular waxes (Eglinton and Hamilton, 1963) make a larger contribution to this thunderstorm precipitation sample than to the rain or snow sample in Fig. 2. Because this sample was collected during the winter when local sources were missing the presence of the wax lipids indicates colian transport of these organic components over a considerable distance. The air mass accompanying this particular storm originated from the Gulf of Mexico and evidently entrained organic matter from growing plants in this warmer region or from conifers encountered during passage up the Missiscippi-Ohio Valley. An abundance of the relatively habile $C_{1}$ alkenoic acid suggests this transport proceeds quickly. Similar transport of land plant organic matter is sugested in the thunderstorm sample collecied on 3 April (No. 17 in Table 1), which contains a relatively high concentration of longchain $n$-alkanes.

Seasonal changes in fatty acid and $n$-alkane content of rain are shown in Fig. 3. Fall, winter and spring are 

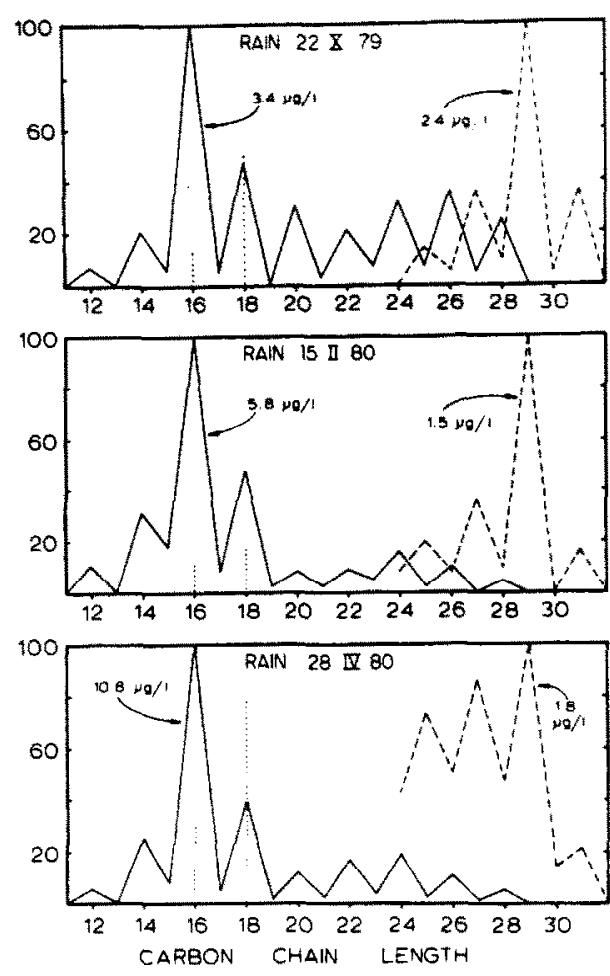

Fig. 3. Comparison of fatty acid and n-alkane contents of rain samples collected in the fall, winter, and spring. Acids and alkanes normalized to the largest component within each compound type. Saturated acids shown as solid lines; unsaturated acids as dotted lines; $n$-alkanes as dashed lines.

represented by these samples, and they all have large contributions of $C_{16}$ and $C_{18}$ acids and of $C_{27}$ and $C_{29}$ $n$-alkanes. Fall and spring rain samples contain proportionally more of the wax-type alkanes and more $C_{22}$ to $C_{28}$ acids, also of a wax origin, than does the winter sample. In addition, the amounts of alkenoic acids are higher in the fall and spring samples. These differences indicate a local input of biologically derived compounds to the overall well-mixed organic matter loading of the troposphere during the fall and spring. Although we have no data at present to verify a similar summer input, this is likely.

A general trend of decreasing concentrations of extractable organic compounds is present in Table 1 for rain samples collected from October to December. This follows the dying off of deciduous foliage and ground cover and ensuing loss of local sources of fatty acids and hydrocarbons which accompanies this seasonal change. During April, a dramatic increase in concentrations occurs, and this accompanies the return of local vegetation with its potential contribution of organic matter to the atmosphere. Indeed, pollen was clearly present in these rain samples and not in any from the fall or winter. Extractable materials no doubt were added to the totals in Table 1 from this airborne plant matter. However, these trends of decreasing and increasing concentrations accompany corresponding increasing and decreasing volumes of precipitation in the events sampled. This inverse relationship agrees with other studies (cf. Gagosian et al., 1981b) and indicates that the early stages of rainfall scavenge the majority of available organic matter from the atmosphere and that subsequent stages mostly dilute the concentrations of samples collected by procedures like ours. The presence or absence of local organic matter sources complicates this picture, yet the implication remains that there is a finite atmospheric organic loading which can be carried down by a given precipitation event, regardless of intensity or duration.

Concentrations of compounds in winter rain samples are variable but consistently contain only small contributions of unsaturated acids and of longchain acids and alkanes. Because large amounts of these types of molecules indicate local inputs of organic matter, their low abundance suggests that most of the material in winter precipitation is from distant rather than local sources and has been wellmixed during transport. In precipitation samples collected during the spring, the amount of unsaturated $\mathrm{C}_{18}$ acid increases relative to its saturated analog (Table 1). Because of the instability of unsaturated compounds after release from their biological sources, a high ratio of unsaturated-to-saturated $C_{18}$ acids has been suggested as an indicator of their recent incorporation into atmospheric samples (Simoneit, personal communication) and hence of local sources. It is only in samples from May that this ratio strongly indicates local input.

If long-range transport is indeed important to the organic matter content of precipitation through most of the year, then the question of atmospheric residence time must be considered. Eichman and coworkers $(1979,1980)$ found that gas phase components constitute up to $99 \%$ of the total tropospheric $n$-alkane loading over the oceans, although the particulate phase contributions increase with molecular weight to reach $6 \%$ for the $\mathrm{C}_{28}$ alkane. They conclude the atmospheric residence time of the gaseous hydrocarbons is of the order of 5 days and that their source must be oceanic in view of this short time. Furthermore, the same conclusion is made for particulate $n$-alkanes. However, their analyses did not include the $\mathrm{C}_{29}$ and higher compounds which Simoneit (1977) and Simoneit et al. (1977) found to be the major hydrocarbon components in eolian dusts collected over the Atlantic ocean and which also dominate our precipitation samples. The molecular distributions of long-chain $n$ alkanes, alkanoic acids, and alcohols present in aerosols from the North Atlantic indicate a predominantly terrigenous source of these lipids, with a minor contribution from marine sources (Simoneit, 1977). As shown in Fig. 1 of Simoneit et al. (1977), the sources of these land-derived dust particles are on the African continent and the prevalent wind patterns can disperse these dusts as far as the Americas. In order for the biogenic character of the lipid materials to be so wellpreserved in these samples, the reactivity of the aerosol 
fraction of organic matter must be lower than that estimated for the gaseous portion by Eichman et al. (1980) or transport must proceed rapidly. Although our study does not provide the supporting experimental data, we suspect the residence time is adequate to allow cross-continental and cross-oceanic transport of fatty acids and hydrocarbons. Indeed, recent measurements indicate PCB air residence times on the order of 6 months in the central Pacific (Atlas and Giam, 1981), and estimates based upon isotopic compositions suggest that $80 \%$ of atmospheric particulate organic carbon over marine areas is of continental origin (Chesselet et al., 1981).

The original goal of our study was to estimate the potential importance of the organic content of rain and snow to large lakes and oceans. The amount of precipitation collected over the 8-month duration of our study is equivalent to $45 \%$ of the annual precipitation for southern Indiana. Extrapolating from the total quantities of different types of organic compounds washed into our $3165 \mathrm{~cm}^{2}$ colloctor by this rain and snow, we calculate the annual input fuxes presented in Table 2. An argument giving credence to this extrapolation is that the types of compounds in our samples were generally quite similar from season to season. This indicates that mixing processes within the troposphere quickly homogenize its organic matter load, hence our analyses are probably a good representation of the character of the annual input of extractable organic matter. Furthermore, we feel enough precipitation events were sampled to provide a reasonably good estimate of the quantity of extractable materials in rain and snow for an annual period.

Our calculated fluxes in Table 2 show that about $80 \%$ of the extractable organic matter in our midwest precipitation samples is fatty acids and $n$-alkane hydrocarbons. Meyers et al. (1980) have estimated the flux of these compound clasces to the bottom of Lake Michigan due to settling sediment particles. These annual rates are $1.8 \mathrm{~g} \mathrm{~m}^{-2}$ for fatty acids and $27 \mathrm{mg} \mathrm{m}^{-2}$ for aliphatic hydrocarbons. It is clear that the fatty acid contribution from precipitation is dwarfed by that from aquatic sources in this lake. Washout is inefficient in scavenging organic pollutants from air over the oceans (Atlas and Giam, 1981), and this may also be true for fatty acids over lakes and land. If all the $n$-alkane input from rain and snow to the water-air interface sinks quickly to the bottom and so escapes degradation, then this can amount to $15 \%$ of the total flux to Lake Michigan sediments-a small but significant amount. A greater significance of this

Table 2. Calculated fluxes of extractable organic material due to precipitation

\begin{tabular}{lc}
\hline Type of organic matter & Annual fux, $\mathrm{mg} \mathrm{m}^{-2}$ \\
\hline Total solvent extract & 25 \\
Total fatty acids $\leqslant \mathrm{C}_{20}$ & 14 \\
Total fatty acids $>\mathrm{C}_{20}$ & 3 \\
Total $n$-alkanes & 4 \\
\hline
\end{tabular}

precipitation input appears to be not in its quantity of organic matter but rather in the types of compounds it contains. As indicated in Fig. 1. long-chain alkanoic acids and $n$-alkanes are present in all the samples we examined. These compounds are not known to have aquatic origins, yet they have been detected in the sediments of the Great Lakes (Meyers and Takeuchi, 1979). They evidently originate from land plants and experience transport to lake locations prior to incorporation into the bottom. It is probable that eolian transport processes, which include rainfall and snowfall, contribute to bringing land-derived organic matter to these lacustrine locations in a manner similar to that found in the marine locations studied by Simoneit (1977), Simoneit et al. (1977) and Gagosian et al. $(1981 \mathrm{a}, \mathrm{b})$.

\section{CONCLUSIONS}

(1) Extractable organic matter in rain and snow collected over an 8-month period at a semi-rural Indiana site is dominated by biologically derived fatty acids $\left(C_{12}\right.$ to $\left.C_{28}\right)$ and $n$-alkanes $\left(C_{23}\right.$ to $\mathrm{C}_{31}$ ).

(2) Lack of major changes in the extractable organic matter composition of precipitation despite seasonal changes in local vegatation suggest considerable long-range transport and mixing of eolian organic matter. This organic matter mixture is carried to earth by rain and snow and is supplemented by local vegetative sources when they are actively growing.

(3) The fatty acid content of these precipitation samples originates primarily from microbial or algal sources; some higher plant cuticular wax acids are present. Hydrocarbons are predominantly $n$-alkanes from higher plant waxy coatings.

(4) Fluxes of these natural extractable materials to the ground are not large. Relative to Lake Michigan sedimeat fluxes, the quantitative contribution of fatty acids is insignificant and hydrocarbons is small. For smaller and more productive lakes, these would be yet less. The precipitation input of land-derived hydrocarbons to aquatic systems may be qualitively important.

Acknowledgements-We thank Bernd R. T. Simoneit, Perry J. Samson and Terry L. Wade for reading early verions of this manuscript and providing thoughteul surgestions for its improvement. This research was supported by funds from the National Science Foundation Marine Chemiatry Division (R. A. H.) and Earth Science Division (P. A. M.).

\section{REFERENCES}

Andren A. W. and Strand J. W. (1981) Atmospheric deposition of particulate organic carbon and polyaromatic 
hydrocarbons to Lake Michigan. In Atmospheric Pollutants in Natural Waters (Edited by S. J. Eisenreich), pp. 459-479, Ann Arbor, MI, USA.

Atlas E. and Giam C. S. (1981) Global transport of pollutants: ambient concentrations in the remote marine atmosphere. Science 211, 163-165.

Broddin G., Cautreels W. and Van Cauwenberghe K. (1980) On the aliphatic and polyaromatic hydrocarbon levels in urban and background aerosols from Belgium and the Netherlands. Atmospheric Environment 14, 895-910.

Chesselet R., Fontugne M., Buat-Menard P., Ezat U. and Lambert C. E. (1981) The origin of particulate organic carbon in the marine atmosphere as indicated by its stable carbon isotopic composition. Geophys. Res. Lett. 8, 345348.

Eglinton G. and Hamilton R. J. (1963) The distribution of alkanes. In Comparative Phytochemistry (Edited by $\mathrm{T}$. Swain), pp. 57-77, Academic Press, New York.

Eichmann R., Neuling P., Ketseridis G., Hahn J., Jaenicke R. and Junge C. (1979) n-Alkane studies in the troposphereI. Gas and particulate concentrations in North Atlantic air. Atmospheric Environment 13, 587-599.

Eichmann R., Ketseridis G., Schebeske G., Jaenicke R., Hahn J., Warneck P. and Junge C. (1980) n-Alkane studies in the troposphere-II. Gas and particulate concentrations in Indian Ocean air. Atmospheric Environment 14, 695703.

Gagosian R. B., Zafiriou O. C., Duce R. A. and Prospero J. M. (1981a) Enewetak tower experiment: Sea-Air Exchange Program (SEAREX). Eos, Trans. Am. Geophys. Un. 62, 81 .

Gagosian R. B., Peltzer E. T. and Zafiriou O. C. [1981b] Organic compounds in vapor phase and rain samples from the Enewetak experiment. SEAREX Newsletter 4, 31-35.

Lunde G., Gether J., Gjos N. and Lande M.-B. S. (1977) Organic micropollutants in precipitation in Norway. Atmospheric Environment 11, 1007-1014.

Meyers P. A. and Takeuchi N. (1979) Fatty acids and hydrocarbons in surfical sediments of Lake Huron. Or. ganic Geochem. 1, 127-138.
Meyers P. A., Edwards S. J. and Eadie B. J. (1980) Fatty acid and hydrocarbon content of settling sediments in Lake Michigan. J. Great Lakes Res. 6, 331-337.

Rasmussen R. A. (1972) What do the hydrocarbons from trees contribute to air pollution? J. Air Pollut. Control Ass. 22, 537-543.

Simoneit B. R. T. (1977) Organic matter in eolian dusts over the Atlantic Ocean. Mar. Chem. 5, 443-464.

Simoneit B. R. T., Chester R. and Eglinton G. (1977) Biogenic lipids in particulates from the lower atmosphere over the eastern Atlantic. Nature 267, 682-685.

Simoneit B. R. T. (1978) The organic chemistry of marine sediments. In Chemical Oceanography Volume 7 (Edited by J. P. Riley and R. Chester), pp. 233-311, Academic Press, London.

Simoneit B. R. T. (1979) Biogenic lipids in eolian particulates collected over the ocean. In Carbonaceous Particles in the Atmosphere, (Edited by T. Novakov). NSF/LBL 9037, pp. 233-244.

Simoneit B. R. T. (1980) Eolian particulates from oceanic and rural areas-their lipids, fulvic and humic acids and residual carbon. In Advances in Organic Geochemistry 1979, (Edited by A. G. Douglas and J. R. Maxwell) pp. 343-352, Pergamon Press, Oxford.

Simoneit B. R. T., Mazurek M. A. and Cahill T. A. (1980) Contamination of Lake Tahoe air basin by high molecular weight petroleum residues. J. Air Pollut. Control Ass. 30, $387-390$

Simoneit B. R. T. (1981) Envir. Sci. Technol. 15, 120

Tripp B. W., Farrington J. W. and Teal J. M. (1981) Unburned coal as a source of hydrocarbons in surface sediments. Mar. Pollut. Bull. 12, 122-126.

Van Vaeck L. and Van Cauwenburghe K. (1978) Cascade impactor measurements of the size distribution of the major classes of organic pollutants in atmospheric particulate matter. Atmospheric Environment 12, 2229-2239.

Van Vack L., Broddin G. and Van Cauwenburghe K. (1979) Differences in particle size distributions of major organic pollutants in ambient aerosols in urban, rural, and seashore areas. Envir. Sci. Technol. 13, 1494-1502. 